\title{
KAJIAN PEMANFAATAN SISTEM PANGAN
}

\author{
Michelle ${ }^{1}$
}

${ }^{1}$ Program Studi S1 Arsitektur, Fakultas Teknik, Universitas Tarumanagara, michelle.rahardja96@gmail.com

\begin{abstract}
Abstrak
Pada generasi milenial banyak faktor yang mempengaruhi gagalnya mencapai keseimbangan pangan, seperti perubahan permintaan dan tren konsumsi. Dalam upaya merespon kondisi krisis pangan global secara lokal, proyek mengusulkan transformasi sistem pangan dimana rantai makanan disingkat menjadi produsen bertemu secara langsung dengan konsumen. Proyek ini diharapkan mampu menjadi contoh dan mengedukasi masyarakat melalui fungsi tanam - distribusi - konsumsi daur ulang untuk mewujudkan keseimbangan pangan masyarakat. Metode perancangan adalah respon terhadap tapak, dimana hasil rancangan yang dihasilkan berasal dari kebutuhan kawasan dan tapak itu sendiri. Sistem hijau dan bekerlanjutan dipilih sebagai pendekatan secara arsitektur untuk mewujudkan keberlanjutan proyek dan bangunan. Rancangan pada tapak adalah menjadikan proyek sebagai wadah kegiatan masyarakat dan kontribusi Ruang Terbuka Hijau bagi kota dan komunitas masyarakat Rawa Belong. Konstruksi dan penggunaan material dirancang sesuai dengan konsep keberlanjutan dengan memperhatikan efisiensi dan daur ulang energi terbarukan seperti cahaya matahari dan limbah pangan serta minim penggunaan penerangan artifisial dan penyejuk udara sehingga dinding fasad dibuat agar bisa memberikan ventilasi alami pada seluruh ruangan. Rancangan bangunan yang bersifat dinamis diharapkan mampu meningkatkan pengunjung sebagai tujuan edukasi dan wisata kuliner serta kegiatan masyarakat di Rawa Belong dan sekitarnya, sesuai dengan program yang diusulkan pada proyek seperti area lokakarya untuk belajar, area restoran dan kafe sebagai daya tarik kuliner, dan area multifungsi untuk kegiatan masyarakat.
\end{abstract}

Kata kunci: berkelanjutan; hijau; masyarakat; pangan; siklus pangan; sistem pangan

\begin{abstract}
Increasing healthier food demand and trend in consumption are causing the failure towards reaching food security. In response to current food crisis, the project proposed to shorten current food chain to transform local food system where the producer meets the consumer. This project aims to be a model to educate people through grow - distribution - cons umption - recycle to create food security for the community. Response to site is use as design method where the response results from the environment and site. Green and sustainable architecture are use as design approach to ensure the sustainability of the program and building. This project intend to be the hub for community and acts as a contribution to green space for the city and community. Constructions and materials design to adapt sustainable concept using renewable energy such as solar energy and by recycling food waste efficiently, in addition to minimize the use of artificial lights and air conditioner resulting to the façade designed to maximize natural ventilation throughout the building. Dynamic building designs are expected to increase visitors as education and culinary destination also as a community center for Rawa Belong community, consistent with the proposed program on this project such as the workshop area for learning, the restaurant and cafe area as a culinary attraction, and a multifunctional area for community activities.
\end{abstract}

Keywords: community; food; food cycle; food system; green; sustainability 


\section{PENDAHULUAN}

\section{Latar Belakang}

Berdasarkan Food Sustainability Index (FSI) oleh Barilla Center for Food \& Nutrition, Indonesia menjadi salah satu negaga terburuk dari 34 negara lainnya dalam hal food loss and waste. (The Economist Intelligence Unit, 2018)

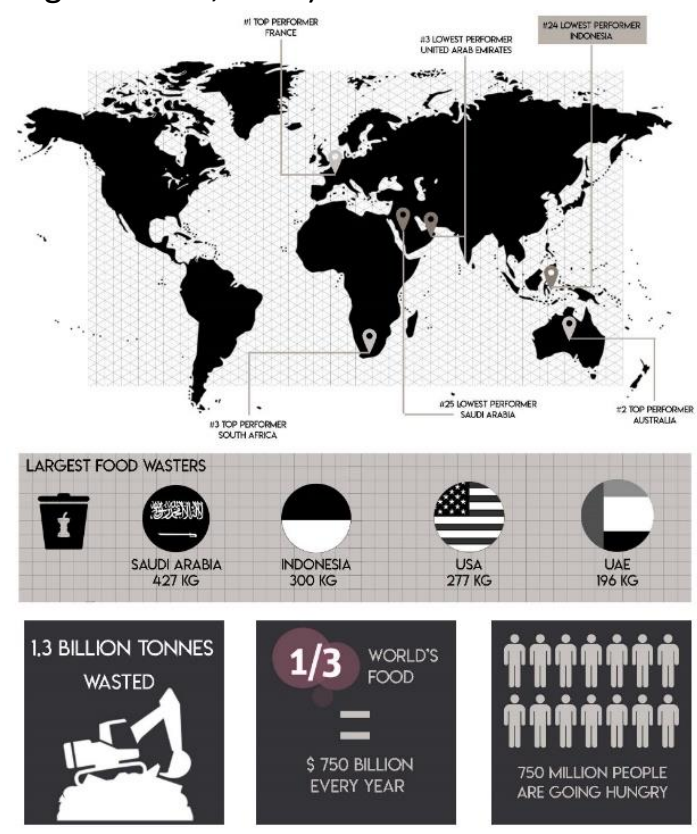

Gambar 1. Grafik negara penghasil sampah makanan terburuk dunia

Sumber: Pribadi berdasarkan data dari Food Sustainability Index

Infrastruktur yang buruk serta minimnya pengetahuan mengenai food crisis turut berkontribusi pada rendahnya nilai Indonesia pada FSI dunia. Banyak dari bahan makanan tersebut bahkan rusak jauh sebelum sampai kepada konsumen. Kontributor lainnya adalah food surplus pada household dan komersial (Retail, Restoran, Hotel, dsb.) yang menuju kepada pembuangan makanan dan krisis pangan. (The Economist Intelligence Unit, 2018)

Kedaruratan ancaman krisis pangan terutama di Asia dikarenakan cepatnya pertumbuhan penduduk, urbanisasi dan berkembangnya selera makanan yang tidak mampu ditopang oleh sistem makanan di daerah tersebut. Penelitian menunjukkan kota di Asia sangat padat dan diprediksi akan bertumbuh hingga 578 juta orang pada tahun 2030. China, Indonesia dan India akan benkontribusi sebanyak 3/4 dari pertumbuhan ini.

Menurut FAO, masih banyak makanan yang rusak saat panen karena sistem pertanian dan irigasi yang tidak terkoordinir dan juga rusak saat menuju ke konsumen dikarenakan buruknya infrastruktur antar daerah. Sehingga ketika makanan sampai di tangan konsumen waktu simpan makanan menjadi lebih pendek. Inflasi bahan makanan yang meningkat pun menambah masalah terhadap sistem makanan di Indonesia. Ada 25,95 juta penduduk miskin di Indonesia (BPS DKI JAKARTA, 2017). Bila permintaan makanan semakin tinggi, namun tidak diimbangi dengan meningkatnya produksi makanan, ancaman food crisis di Indonesia pun semakin nyata, terutama bagi para penduduk miskin.

Terdapat beberapa cara untuk menangani permasalahan food crisis seperti pembuatan food bank untuk penerimaan food surplus dan pendistribusian makanan kepada yang membutuhkan; pembuatan tempat pengolahan dan pendaur ulang sampah organik seperti tps 3R (Reduce, Reuse dan Recycle), bank sampah, dan ITF (Intermediate Treatment Facility); serta pembuatan sustainable vertical urban farming yang membutuhkan lebih sedikit lahan dan pemanfaatan sumber daya yang efektif. (The Economist Intelligence Unit, 2018) 
Di Indonesia, terutama di kota besar, kesadaran akan food crisis sudah semakin meningkat. Beberapa kelompok generasi millennial giat membuat organisasi untuk mengurangi sampah makanan dan sustainable urban farming. Diantaranya, organisasi seperti Garda Pangan dan Food Bank of Indonesia (FOI) yang memiliki program yang serupa yaitu dengan melakukan food rescue dari berbagai industri hospitality (Restoran, Hotel, Bakery). Makanan yang tidak habis dijual pada hari itu disalurkan ke masyarakat pra-sejahtera dengan cara yang santun (Garda-Pangan, 2018).

Selain itu ada perusahaan Waste4Change yang mengambil alih peran pengelolaan sampah. Mereka menjemput sampah yang sudah dipilah dan diolah melalui rekanan untuk sampah non-organik dan sampah organik diolah menjadi kompos. (Waste4Change, 2014)Pada institute Bumi langit, pengunjung diajak untuk belajar dan mengetahui dari mana makanan berasal dan cara bercocok tanam selain dapat menikmati hasil bumi yang telah diolah di restorannya. Selain itu organisasi Bumi Langit juga membuka kelas dimana para murid bisa belajar mengenai tata cara bercocok tanam bahan makanan secara sustainable dengan juga mengola sampah makanan menjadi kompos. (Bumi Langit, 2006)

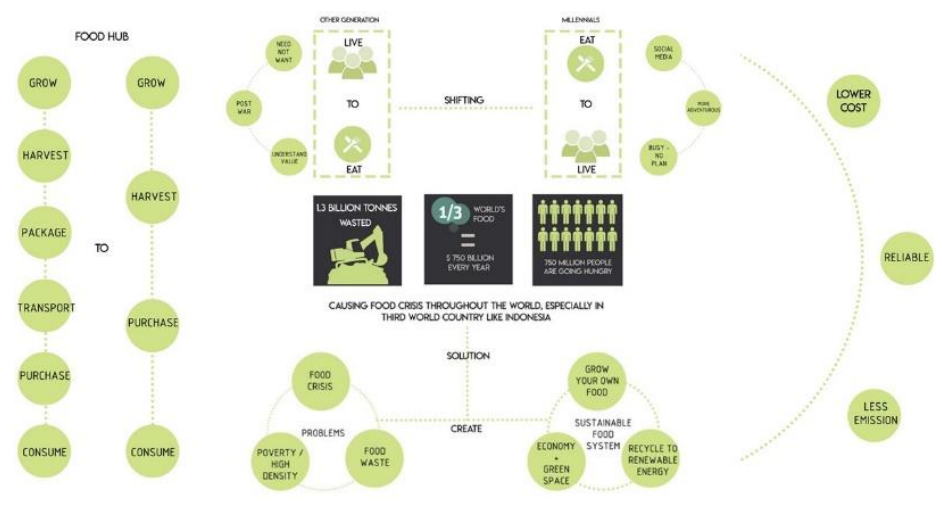

Gambar 2. Diagram permasalahan gaya hidup millennial Sumber: Penulis, 2019

DKI Jakarta merupakan kota dengan angka kepadatan penduduk yang paling tinggi di Indonesia, selain itu merupakan Ibukota pusat pemerintahan, perekonomian dan pariwisata. Dengan padatnya kota Jakarta, gap antar kalangan semakin lebar. Pengaruh gaya hidup di perkotaan juga membuat warga Jakarta terutama generasi millennial menjadi konsumtif, termasuk dalam hal pembelian makanan dan tidak menghabiskan makanan, hal ini jugalah yang berkontribusi pada meningkatnya produksi food waste di DKI Jakarta. (Kresna, 2017)

Generasi Millennial mengalami perubahan gaya hidup dibanding generasi sebelumnya, mereka menganggap makanan sebagai sebuah gaya dan nilai hidup. Hal inilah yang memperparah krisis makanan dunia, selain kemiskinan dan kepadatan penduduk. Dalam upaya mencapai keseimbangan pangan dan mencegah krisis pangan, maka di usulkan untuk mengubah gaya hidup dengan menanam makanan sendiri, mendaur ulang residu baik makanan maupun organic menjadi energy terbarukan yang bermanfaat, mendistribusikan makanan berlebih - food surplus kepada yang membutuhkan, hingga membuat wadah kegiatan yang menghubungkan ekonomi dan Ruang Terbuka Hijau.

\section{KAJIAN LITERATUR}

\section{Tipe - Perilaku dan Nilai Kesejamanan (Millenials)}

Millennials atau Generasi $Y$ adalah istilah yang digunakan untuk mendeskripsikan individual yang mencapai usia dewasa atau produktif sekitar abad ke 21. Kisaran tahun kelahiran millennials merupakan sebuah perdebatan di kalangan para ahli dan juga masyarakat. (Rouse \& Haughn, 2014) Namun, menurut Neil Howe dan William Strauss pada 
bukunya yang berjudul Generations: The History of America's Future, 1584 to 2069, millennials merupakan mereka yang lahir pada tahun 1982 hingga 2004.

Population breakdown by largest generations

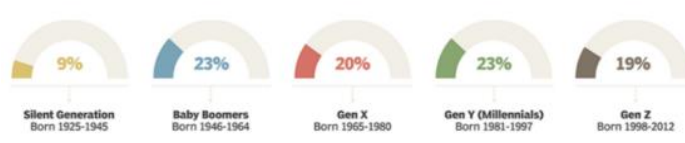

Gambar 3. Grafik populasi generasi

Sumber: Rouse \& Haughn, 2014

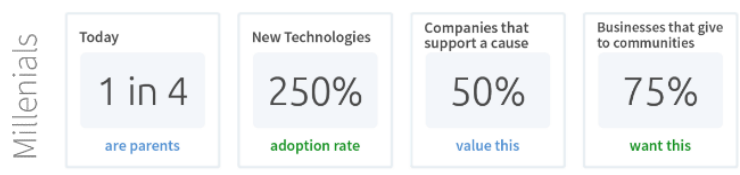

Gambar 4. Grafik data perkembangan generasi millenial Sumber: Rouse \& Haughn, 2014

\begin{abstract}
"Millennials are unlike any other youth generation in living memory. They are more numerous, more affluent, better educated, and more ethnically diverse. More important, they are beginning to manifest a wide array of positive social habits that older people no longer associate with youth, including a new focus on teamwork, achievement, modesty, and good conduct." - Neil Howe and William Strauss
\end{abstract}

Hidup di dunia yang terpengaruh perkembangan teknologi dan social media millennials tumbuh mendominasi pasar dan tenaga kerja, menjadi sasaran utama dari berbagai bidang meliputi teknologi, gaya hidup, desain dan arsitektur. Tapi dibandingkan dengan generasi sebelumnya,, millennials tidak percaya pada sistem advertising tradisional, maka mereka akan meresearch secara independen melalui internet. Melalui dunia internet yang tanpa batas, millennials menjadi indivual yang lebih toleran terhadap perbedaan dan sangat cepat belajar.

Gaya hidup millennials adalah salah satu aspek yang dipengaruhi oleh globalisasi, urbanisasi, dan teknologi yang terus berubah. Menurut Goldman Sachs, millennials lebih lama tinggal bersama orang tua dan tidak tertarik pada 'ownership' yang membantu berkembangnya sistem 'sharing economy'. (Goldman Sachs \& Co. LLC, 2015)
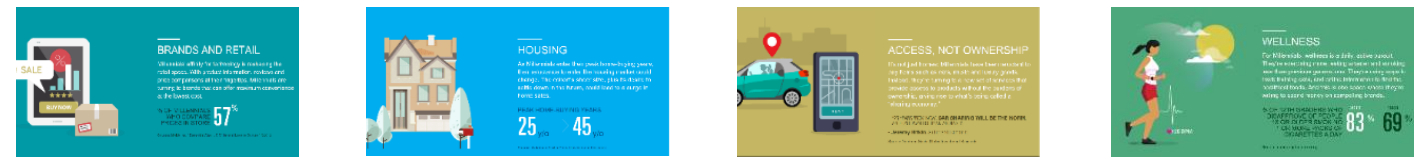

Gambar 5. Grafik gaya hidup millennial

Sumber: Goldman Sachs \& Co. LLC, 2015

Millennials juga sudah self-aware dengan isu sosial dan lingkungan yang ada. Studi "Cone Millennial Cause" menunjukkan bahwa lebih dari 80\% dari reponden survey menjadi volunteer baik mingguan, bulanan ataupun sekali atau beberapa kali dalam setahun. (Calbert, 2018) Mereka sudah mulai melakukan perubahan secara aktif dengan tindakan yang dipengaruhi oleh tren dari berbagai budaya dan marak di social media. Mereka pun mampu meresearch gaya hidup dan tren terkini secara independent dari internet. Gaya hidup selain kebutuhan pribadi, menjadi sebuah tren untuk menunjukkan diri pada social media.

Dengan berkembangnya gaya hidup millennial, maka arsitektur dunia juga turut berubah. Menurut Nico Lopez dalam artikel Gen $Y$ : Millennials in Architecture yang terbit pada situs TMD Studio, arsitek millennial terinspirasi dari apa yang mereka lihat di komputer, handphone 
dan tablet. Selain itu, karena secara finansial millennials mengindari beban dari 'ownership', yang menaikkan pamor 'sharing economy' atau menurut beberapa orang 'minimalist movement', dimana pakaian, rumah dan kendaraan pun sekarang merupakan komoditi bersama ( contohnya : https://id.styletheory.co/, co-living, Grab dan Gojek).

We can't just build buildings in cities and expect them to work. They need to be curated. Nico Lopez, Gen Y : Millennials in Architecture. Sebagai gantinya, millennials lebih mementingkan experiences dan memories pada area kesehatan, travel, arts and culture, makan di restoran dan socialising dengan sebayanya. Menurut generasi ini, pengalaman tersebut memiliki nilai yang lebih tinggi dibandingkan dengan kepemilkan benda. (Lopez, 2017) Artinya, bagi para arsitek tidak bisa hanya membangun sebuah bangunan yang sesuai dengan tipe yang telah ada serta berdasarkan fungsi saja, melainkan sebuah pengalaman dalam sebuah karya arsitektur. Dengan begitu arsitek mampu menjadi pihak yang mendorong dan mempengaruhi perubahan ini, melampaui batas-batas tradisional arsitektur dan terus menggunakan cara baru dan inovatif dalam desain yang sesuai dengan perkembangan jaman. (Dewhirst, 2018)

\section{Limbah Pangan - Food Waste}

Food waste, or losses, merujuk pada berkurangnya massa makanan yang layak dikonsumsi selama tahap Food Supply Chain (FSC). Dampak ke lingkungan, sosial dan ekonomi semakin nyata dan food waste sendiri diakui menjadi pusat resolusi yang sustainable dari masalah sampah dunia. (Papargyropoulou, Lozano, Steinberger, Wright, \& Ujang, 2014) Anggapan bahwa permasalahan dari food waste sendiri hanya timbul pada tahap konsumsi atau akhir merupakan salah besar. Masalah food waste dimulai dari awal Food Supply Chain (FSC), bahkan hingga pada tahap waste management dimana limbah umumnya hanya dibuang tanpa diolah kembali. (Gille, Alexander, \& Gergson, 2013)

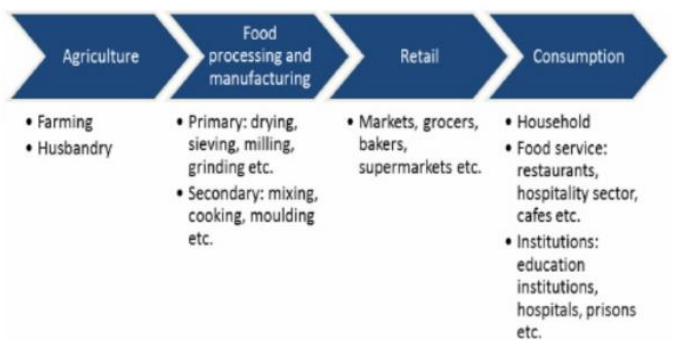

Gambar 6. Diagram food system

Sumber: Papargyropoulou, Lozano, Steinberger, Wright, \& Ujang, 2014

Responnya adalah meningkatnya prioritas dari negara dan daerah dalam pengelolaan limbah makanan, serta kesadaran akan pentingnya distribusi makanan dan tindakan preventif untuk mengurangi limbah. (Papargyropoulou, Lozano, Steinberger, Wright, \& Ujang, 2014)

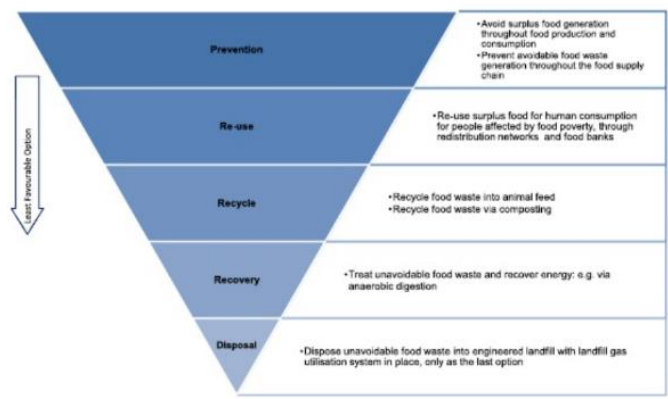

Gambar 7. Hirarki food waste

Sumber: Papargyropoulou, Lozano, Steinberger, Wright, \& Ujang, 2014 
Beberapa metode yang dilakukan untuk mengurangi masalah tersebut adalah pengaturan produksi dan konsumsi yang sustainable. Produksi yang sustainable seperti cleaner production, pollution prevention, eco-efficiency dan green productivity. Konsumsi sustainable berfokus menjembatani konsumen dengan produk dan produsen, contohnya dengan eco-labeling, sustainable procurement, supply chain management, waste minimization, recycling dan resource efficiency measures. (Papargyropoulou, Lozano, Steinberger, Wright, \& Ujang, 2014) Isu yang berhubungan dengan food waste adalah food surplus, dimana keduanya sering dianggap sama, namun perbedaan food surplus dan food waste sangat berpengaruh pada penanganan food waste yang sustainable. Food Surplus merupakan makanan yang berlebih dari apa yang kita butuhkan, dan limbah makanan adalah produk dari food surplus itu sendiri. Dengan menjembatani pihak yang memiliki makanan dengan yang kurang makanan akan membentuk sebuah food circle yang sustainable, dimana limbah makanan menjadi minimal (Papargyropoulou, Lozano, Steinberger, Wright, \& Ujang, 2014).

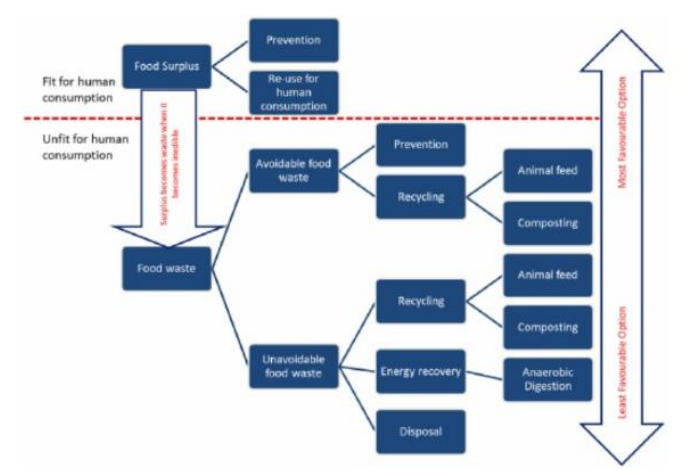

Gambar 8. Framework food surplus dan food waste

Sumber: Papargyropoulou, Lozano, Steinberger, Wright, \& Ujang, 2014

\section{Distribusi Pangan - Food Distribution}

Secara umum, distribusi makanan terdiri dari berbagai perusahaan, organisasi dan program yang mengumpulkan makanan dari produsen, menyimpannya di gudang, dan kemudian mendistribusikan makanan ke retail, restoran, kafe, program bantuan pemerintah dan lainnya. Distributor menangani pengangkutan dan penyimpanan makanan saat perjalanan dari produsen ke operator layanan makanan. Beberapa distributor memiliki spesialisasi dalam produk makanan tertentu seperti makanan laut atau buah dan sayuran. Beberapa mungkin bekerja untuk produsen makanan tertentu. Sebagian besar distributor makanan bersifat independen, yang memudahkan produsen untuk membuat supply chain hanya dengan menyewa distributor yang memenuhi kebutuhan mereka Fram, 2019.

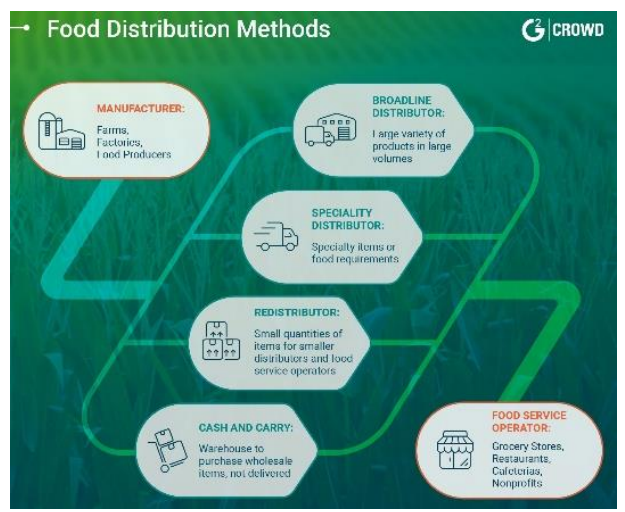

Gambar 9. Metode distribusi makanan. Sumber: https://learn.g2.com/food-distribution 
Beberapa distributor makanan menggunakan gudang untuk menyimpan makanan dalam waktu singkat, dan yang lainnya hanya menggunakan truk berpendingin untuk mengangkut barang langsung ke operator layanan makanan. Jangka waktu dan metode transportasi sepenuhnya tergantung pada jenis makanan yang didistribusikan. Beberapa distributor makanan membeli langsung dari produsen, dalam hal ini distributor makanan hanya memenuhi pesanan. Tetapi dalam banyak kasus, distributor makanan menjual langsung ke operator layanan makanan, yang memungkinkan produsen untuk fokus pada hasil pangan mereka daripada mempertahankan dan mendapatkan pelanggan. (Fram, 2019)

\section{Pertanian Urban Vertikal - Urban Vertical Farming}

Tidak semua makanan yang tersedia mampu dirasakan oleh semua orang - food security (keseimbangan pangan). Salah satu usulan untuk memenuhi kebutuhan dan asupan gizi makanan adalah dengan menanam makanan sendiri - grow your own food yang menjadi dasar self - sufficiency. Pada self - sufficiency, seseorang tidak lagi menjadi tergantung pada sistem rantai makanan, namun ia memenuhi kebutuhan makanannya dengan cara bercocok tanam.

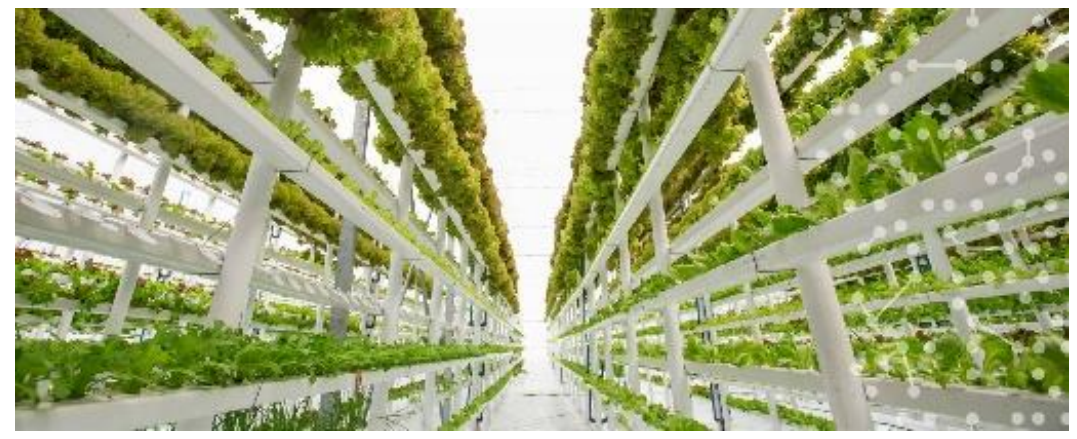

Gambar 10. Contoh sistem vertical farming

Sumber: https://autogrow.com/your-growing-environment/vertical-farming

Pada daerah perkotaan dengan kepadatan tinggi dimana tanah menjadi langka, dapat digunakan sistem vertical farming. (Rossum, 2019) Vertical farming yaitu praktek memproduksi bahan makanan dan tanaman obat / herbal secara vertikal dengan modul yang ditumpuk keatas, sehingga bisa ditanaman pada bidang vertikal seperti dinding ataupun digantung untuk menghemat penggunaan ruang. (Wikipedia, 2015)

Vertical farming bisa dilakukan indoor maupun outdoor. Secara indoor dengan menggunakan teknik 'Controlled - Environment Agriculture' yang mengontol sinar, kelembaban, temperatur, udara, dan sebagainya. Selain itu juga bisa menggunakan teknik green house, dimana sinar matahari bisa dikombinasikan dengan sinar artificial dan reflector metal. (Wikipedia, 2015) Vertical farming juga bisa menggunakan media lain selain tanah yaitu air, air, arang sekam, serabut kelapa, pecahan batu, dan moss (Rossum, 2019).

\section{Konsumsi Pangan - Food Consumption}

Meningkatnya permintaan konsumsi makanan di Indonesia menjadi tantangan serius bagi kebijakan pangan yang akan berdampak pada tahun mendatang. Kebijakan yang ada untuk meningkatkan produksi makanan pokok mungkin tidak memadai untuk memenuhi peningkatan permintaan pangan. (Arifin, Achsani, Martianto, Sari, \& Firdaus, 2018) Populasi yang meningkat pada kelas menengah di Indonesia, dan tingkat urbanisasi yang tinggi telah menyebabkan perubahan dalam pola makanan dan permintaan makanan. Pendapatan dan pengetahuan yang lebih membuat konsumen mengkonsumsi makanan yang lebih beragam. 


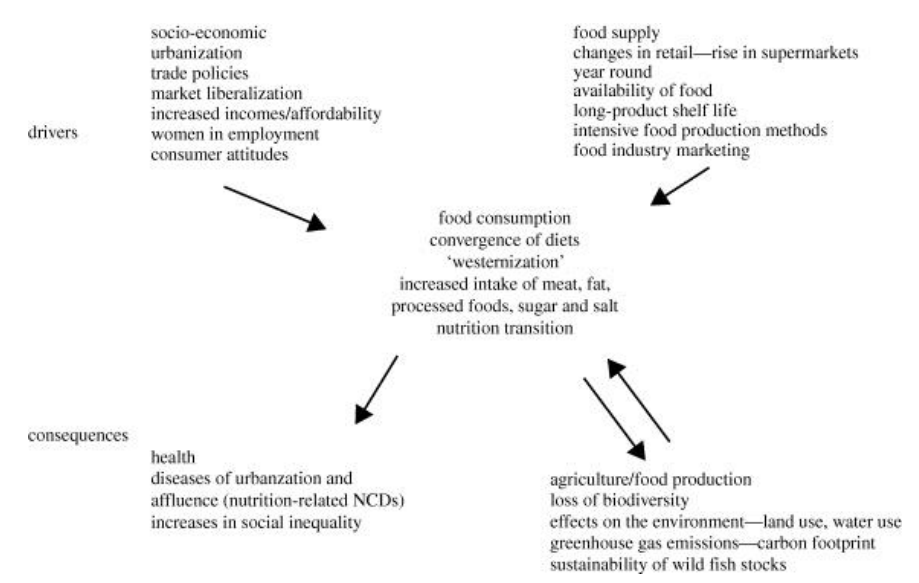

Gambar 11. Hubungan antara pola konsumsi, pendorongnya dan konsekuensi Sumber: Kearney, 2010

Permintaan pangan masa depan di Indonesia ditentukan oleh permintaan yang ada, pendapatan, harga dan komposisinya, ketersediaan makanan, aksesibilitas makanan dan pilihan makanan, yang pada gilirannya dapat dipengaruhi oleh geografi, demografi, pendapatan, SES (Socioeconomics Status), urbanisasi, globalisasi, pemasaran, agama, budaya dan sikap konsumen yang mempengaruhi perilaku dan tren konsumsi. (Kearney, 2010) Kebijakan untuk mengatur distribusi pangan harus fokus pada keseimbangan antara manajemen sisi permintaan dan sisi penawaran atau peningkatan produktivitas, karena sebagian besar pusat produksi bahan pangan berlokasi di pulau Jawa. Karena sebagian besar produk pangan dipasarkan melalui kerjasama dengan pasar induk, kota-kota besar dan menengah harus menerapkan kebijakan perencanaan tata ruang dan zonasi untuk pengelolaan limbah end-to-end di pasar tradisional. (Arifin, Achsani, Martianto, Sari, \& Firdaus, 2018)

\section{Psikologi dan Arsitektur}

Social learning theory oleh Albert Bandura (1986) percaya bahwa perilaku baru dapat tercipta lelalui dua tipe pembelajaran : Observational learning dan Enactive learning. Dalam observational learning, Bandura mempercayai bahwa pengamatan memungkinkan manusia untuk belajar tanpa melakukan perilaku yang dimaksud itu sendiri. Bandura juga mempercayai bahwa observational learning jauh lebih efisien dibandingkan dengan belajar dari pengalaman langsung. Dengan mengamati perilaku dari manusia lain, kita bisa belajar dan meniru perilaku orang tersebut. Inti dari observational learning ini adalah modeling. Pembelajaran melalui modeling melibatkan proses kognitif dan bukan hanya menitu atau imitasi, dengan mengingat dan menyimpan informasi tersebut untuk digunakan pada masa depan. (Feist \& Feist, 2013)

Enactive learning memungkinkan manusia untuk memperoleh pola perilaku yang baru melalui direct experience dengan memikirkan dan mengevaluasi konsekuensi dari perilaku mereka. Proses tersebut memungkinkan orang untuk memiliki tingkat kontrol atas peristiwa yang membentuk jalan hidup mereka. Kontrol berhubungan dengan interaksi antara person variables, behavior dan environment. (Feist \& Feist, 2013) Triadic Reciprocal Determinsim menjelaskan bahwa setiap aksi yang dilakukan oleh manusia disebabkan oleh faktor eksternal, yaitu lingkungan dan manusia dalam bentuk fisik (gender, size, social position) maupun kognitif (thoughts, memory, judgement, dsb)

Psikologi dan arsitektur memiliki efek pada manusia dalam segi pemikiran, kemampuan kognitif, kesejahteraan mental dan fisik serta emosi. Arsitektur mampu mempengaruhi dan mengendalikan perilaku manusia dengan memahami pengaruh lingkungan terhadap perilaku manusia lewat desain. (Margarete, 2018) "Spaces determine our behavior - for the most part without our conscious perception" - Dr. Deinsberger-Deinsweger. Bagaimana suatu arsitektur dibentuk mampu mempengaruhi cara seseorang berperilaku (Vats, 2017) (contoh : dengan alur bangunan) seperti dalam proses edukasi. Dengan memahami target dari edukasi (dalam 
hal ini millennials), desain arsitektur dapat dibuat untuk memotivasi proses dan pola edukasi baik secara observational maupun enactive, sehingga tujuan dan fungsi dari bangunan mampu terpenuhi secara optimal.

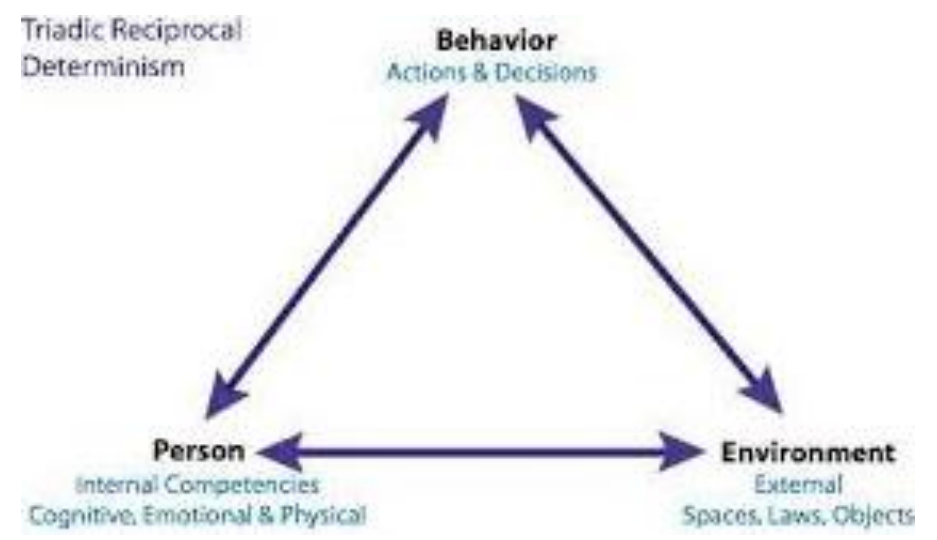

Gambar 12. Grafik Triadic Reciprocal Determinsim

Sumber: Feist \& Feist, 2013

\section{METODE}

Metode perancangan yang digunakan pada proyek adalah response to site, dimana proses racangan dimulai dengan pemilihan isu - food crisis dan pembuatan program kegiatan dan ruang - ruang yang dibutuhkan. Setelah itu dibuat kriteria tapak yang mampu menunjang kegiatan dan kepentingan program yang terlah dibuat. Konsep dan bentuk bangunan serta fasad dan landscape pun dirancang untuk merespon keadaan yang terdapat pada tapak.

Contextualism, atau arsitektur kontekstual, adalah prinsip desain di mana arsitektur dirancang sebagai respons terhadap lingkungan perkotaan dan alami yang spesifik. Dalam pengertian arsitektural, konteks dapat didefinisikan sebagai memberi makna pada berbagai bagian bangunan melalui referensi ke lingkungannya yang lebih luas. Alih-alih menjadi gaya arsitektur yang spesifik, contextualism dapat dilihat sebagai sebuah nilai yang menggabungkan tidak hanya konteks langsung tetapi konteks bangunan yang lebih luas ke dalam desain. Konteks bangunan mencakup faktor fisik / alami (misalnya, sungai yang berdekatan), dan faktor sosial budaya (misalnya, penggunaan situs sebelumnya), dan lainnya. Faktor-faktor ini dapat dianalisis, diadaptasi dan diadopsi untuk mengintegrasikan bangunan ke dalam konteksnya. (Designing Buildings, 2018)

\section{Pendekatan Arsitektur}

Sustainability architecture mengacu pada bangunan yang berfokus pada renewal energy, sustainable material, water conservation, site development dan quality of indoor ambience. Dasar dari sustainable architecture adalah hanya menggunakan teknik dan material yang environmentally friendly selama proses pembangunan, juga berupaya meminimalisir dampak negative dari bangunan melalui konsumsi energy dan pengembangan ruang yang efisien. (Garofalo, 2018)

Penggunaan bahan bangunan alami dan daur ulang dikombinasikan dengan sumber energi terbarukan biasanya membuat sustainable architecture jauh lebih murah untuk dibangun dan dipelihara. Selain manfaat bagi lingkungan dan penghematan biaya, salah satu manfaat terbesar sustainable architecture adalah gaya dan desain tidak perlu dikompromikan oleh penekanan pada bahan alami dan konservasi energi. Bahkan, Sustainable architecture arsitektur berkelanjutan menekankan bukan hanya pada gaya dan desain, tetapi juga inovasi. (SH Architecture, 2016). 


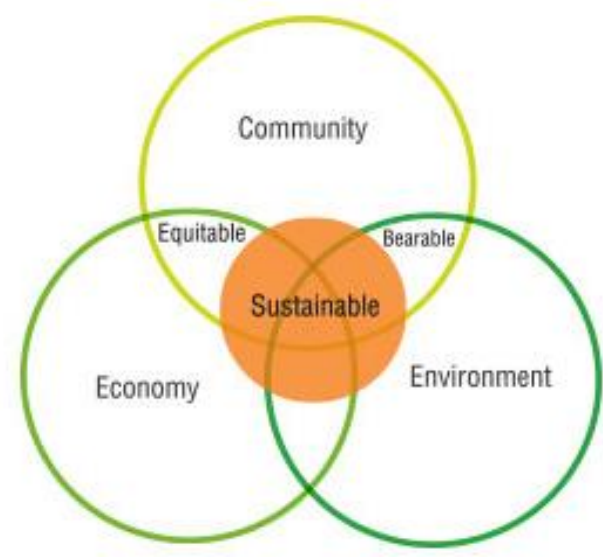

Gambar 13. Diagram sustainable

Sumber: SH Architecture, 2016

Green architecture atau green design mengacu pada pendekatan yang dilakukan dalam mendesain bangunan yang meminimalisir efek dari proyek konstruksi terhadap kesehatan dan lingkungan manusia. Para pelaku arsitektur ini berusaha untuk menyelamatkan udara, air dan lingkungan dengan memilih untuk menggunakan material dan konstruksi yang eco - friendly. Karakteristik green building pada umumnya adalah : sistem ventilasi yang dedesain secara efektif agar hangat maupun sejuk, menggunakan perangkat energy - efficient, sistem pipa yang menghemat air, desain landscape dengan tanaman yang berasal dari tapak dan juga penanaman untuk memaksimalkan passive solar energy, tidak merusak lingkungan, memiliki sumber energy terbarukan seperi matahari atau angin, tidak menggunakan bahan sintetis ataupun beracun dalam bangunan, penggunaan ruang yang efisien, memiliki rain water harvesting dan mendaur ulang grey water dari bangunan (Craven, 2019).

\section{Program Kegiatan dan Program Ruang}

Program kegiatan dan unit - unit yang terdapat pada bangunan untuk menunjang fungsi bangunan. Program ruang dibuat dengan menghubungkan fungsi - fungsi dari food system dari satu dengan lainnya, sehingga dalam kesatuan holistic bangunan menyediakan wadah bagi sebuah food cycle bagi komunitas.

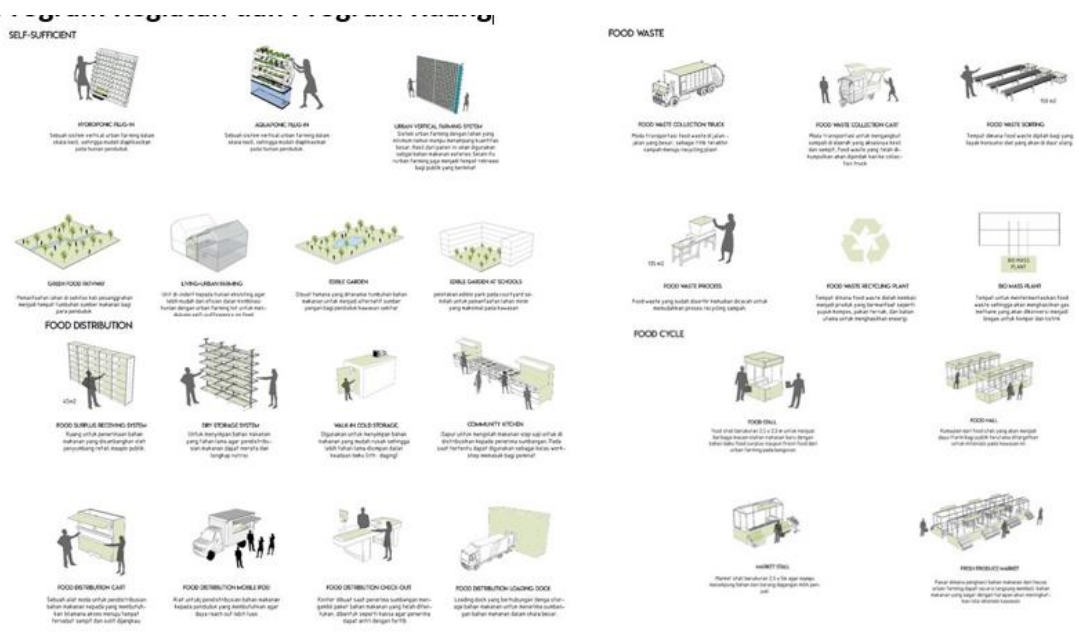

Gambar 14. Diagram program kegiatan pada proyek Sumber: Penulis, 2019 


\section{Tapak}

\section{Kriteria Tapak}

Kriteria tapak adalah tapak terletak di atau dekat dengan kawasan permukiman padat penduduk ; pada kawasan tersebut dekat dengan pusat kegiatan masyarakat ; pada kawasan tapak terdapat pusat kegiatan / tempat tinggal generasi millennial ; kawasan tapak memiliki aktifitas yang ramai ; memiliki KDB yang tidak terlalu tinggi sekitar $1-4$ lantai.

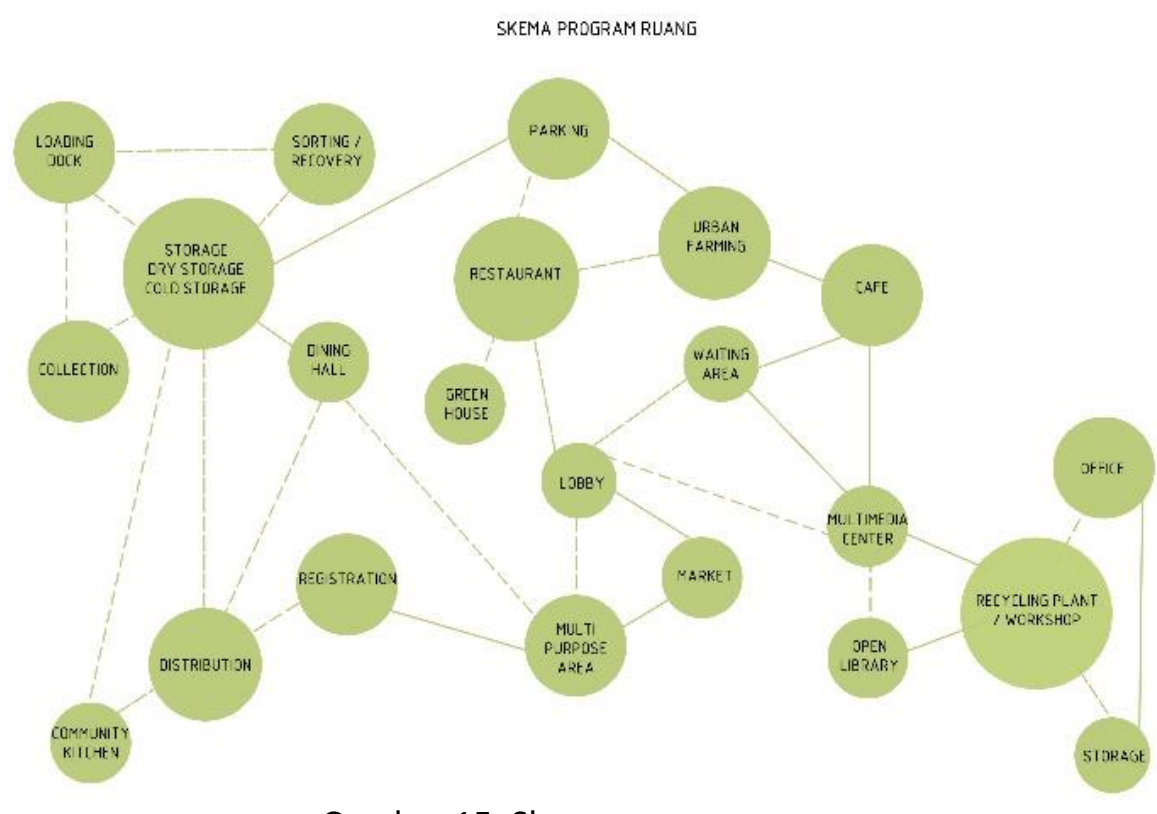

Gambar 15. Skema program ruang

Sumber: Penulis, 2019

\section{Pengamatan Kawasan}

Kota Jakarta Barat dipilih karena terdapat salah satu pusat promosi hasil hortikultura di Jakarta. Kepadatan permukiman penduduk dan tingkat persebaran kumuh yang dukup tinggi dibanding kota lainnya juga menjadi salah satu faktor penentu pemilihan kota. Banyaknya penduduk miskin yang umumnya menjadi korban krisis pangan menjadi faktor yang ikut dipertimbangkan. Dari seluruh kecamatan di Jakarta Barat, kecamatan Kebon Jeruk dipilih karena daerahnya di dominasi oleh permukiman dengan kepadatan penduduk yang cukup tinggi. Berada di second layer Jakarta dan dekat banyak titik kegiatan millennials seperti perkantoran, museum, universitas hingga CBD dan superblock.

Analisa Tapak

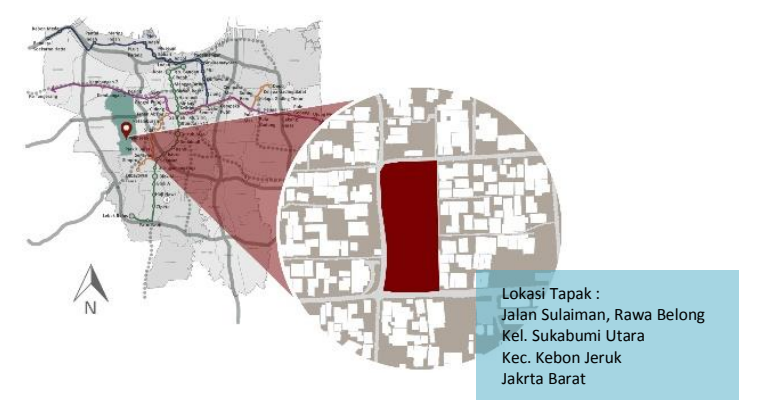

Gambar 16. Keberadaan proyek terhadap kota Jakarta Sumber: Penulis, 2019 
Lokasi Tapak terletak di Rawa Belong, Kelurahan Sukabumi Utara, Kecamatan Kebon Jeruk, Jakarta Barat. Lokasi tapak berdekatan dengan Pusat Hortikultura Pasar Bunga Rawa Belong dimana pasar tersebut menjadi daya Tarik dan pusat keramaian di daerah tersebut. Lokasi sekitar tapak dipenuhi rumah padat penduduk dengan tinggi, fungsi dan fasad yang beragam (amorf). Jalan pada sekitar tapak cukup kecil ( $5-7 \mathrm{~m}$ ) namun dapat dilewati oleh kendaraan bermotor dengan keadaan jalur pedestrian yang sangat buruk ( digunakan untuk parkir, berjualan, keadaan tidak terawat / rusak ). Walaupun menjadi pusat hortikultura, baik pada sekitar tapak hingga pada tingkat kelurahan tidak terdapat Ruang Terbuka Hijau maupun pusat kegiatan masyarakat (community center). Pada kelurahan Sukabumi Utara ini hanya terdapat 1 buah pasar yang mengambil jalan gang perumahan sebagai tempat berjualan, berjarak kira kira $200 \mathrm{~m}$ dari tapak.

\section{DISKUSI DAN HASIL}

\section{Rancangan Pada Tapak}

Konsep rancangan massa pada tapak dibuat dengan mengambil konteks dari kawasan sekitar tapak. Massa dibentuk memanjang sesuai bentuk tapak, kemudian massa dipecah mengikuti konteks bangunan sekitar tapak yang amorf dengan ukuran kecil-sedang dengan ketinggian bangunan tidak lebih dari 4 lantai. Massa bangunan diputar agar setiap massa memiliki view dalam tapak yang berbeda dan memiliki void untuk rain water harvesting. Setelah itu massa bangunan dibuat dinamis seperti konteks kawasan yang organic, begitu juga dengan ketinggian antar massa yang mendukung komunikasi antar ruang yang lebih menarik. Dibuat jembatan yang menghubungkan antar massa agar lebih mudah diakses.

\section{Rancangan Bangunan}

Lantai dasar diperuntukkan bagi public space yang bisa diakses oleh siapa saja dengan pintuk masuk yang terkontrol. Terdapat juga lahan parkir bagi sepeda dan kendaraan bermotor dengan akses masuk khusus. Pada bagian depan bangunan dibuat multi - purpose space yang mampu menampung kegiatan seperti food hall, fresh produce market, hingga live music ataupun untuk kegiatan warga. Selain itu lantai dasar bangunan juga digunakan sebagai kontribusi Ruang Terbuka Hijau bagi masyarakat Rawa Belong yang padat penduduk. Massa yang terpecah saling dihubungkan oleh sky bridge agar menjadi suatu 'experience' ketika menjelajah seluruh ruang bangunan. Atap dan bridge dengan bahan transparan memungkinkan masuknya cahaya matahari ke seluruh bagian bangunan.

\section{Sirkulasi Dalam Bangunan}

Pengunjung dapat memasuki tapak melalu bagian depan - multi - purpose space dan juga akses masuk dari lahan parkir kendaraan bermotor dan parker sepeda. Pengunjung bisa mengelilingi tapak dengan berjalan di paving block atau duduk di bawah pohon pada bench yang disediakan untuk menikmati space dan landscape pada tapak dan juga penghubung antar massa pada lantai dasar. Akses menuju lantai selanjutnya bisa menggunakan tangga dan sky bridge yang mehubungkan massa. 

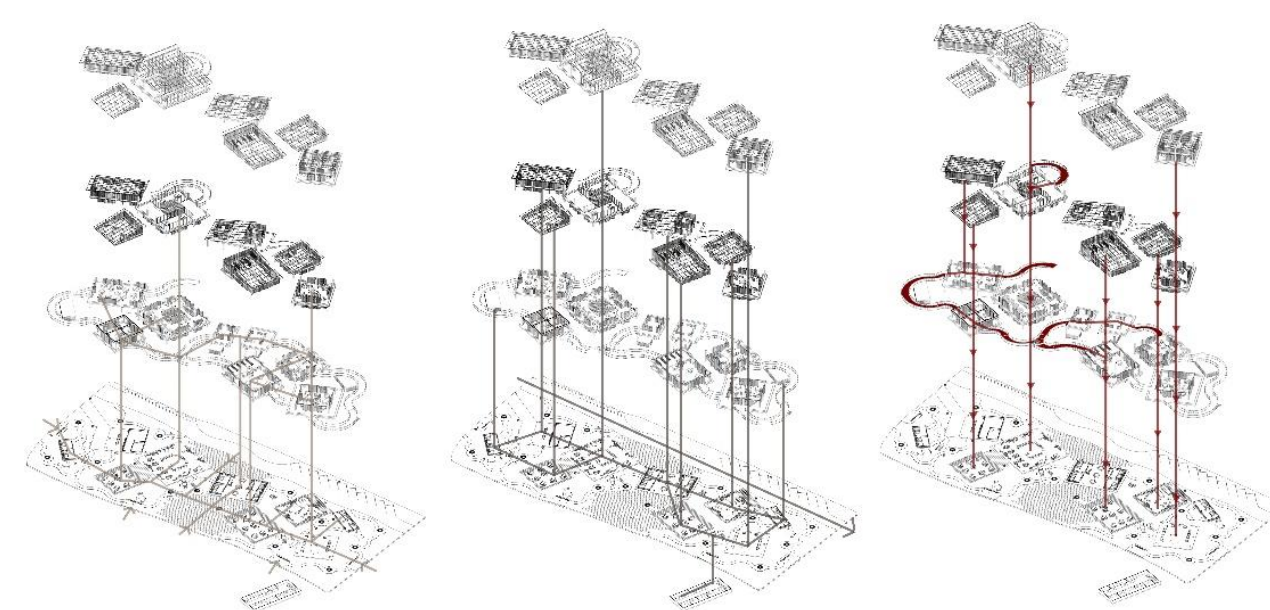

Gambar 17. Sirkulasi Pengunjung, Sirkulasi Servis, dan Sirkulasi Darurat

Sumber: Penulis, 2019

Sirkulasi service menggunakan akses yang sama seperti pengunjung kecuali pada lantai basement yang tertutup hanya untuk daerah service dan pengelolaan bangunan. Limbah makanan dan organic yang dihasilkan akan dibawa ke recycling plant untuk diolah menjadi kompos atau energy listrik bagi bangunan. Proses pengangkutan limbah dan produk hasil daur ulang adalah sebuah proses contoh pemanfaatan sistem makanan. Loading dock terkoneksi dengan storage sehingga memudahkan penerimaan, penyortiran, dan penyimpanan pangan.

Dalam situasi darurat, pengunjung dapat langsung menggunakan tangga dan ramp menuju lantai dasar dan menyelamatkan diri. Pada massa bangunan yang tidak memiliki akses vertical secara langsung dapat menggunakan sky bridge menuju massa bangunan di sebelahnya dan menju lantai dasar seperti biasa dikarenakan ketinggian bangunan yang tidak terlalu tinggi. Dari basement dapat menggunakan ramp menuju lantai dasar bangunan. Titik aman berkumpul terdapat di bagian depan bangunan yaitu multi - purpose space yang lapang dan langsung menju keluar dari tapak.

\section{Sistem MEP Bangunan}

Sistem bangunan baik kelistrikan, udara, pencahayaan dan tata olah sampah dirancang dengan nilai sustainability. Pada sistem air terdapat kantung antar massa bangunan yang dapat digunakan untuk rain water harvesting. Sedangkan grey water dan storm water ditampung dan difilter kemudian digunakan kembali untuk tanaman dan toilet pada bangunan.

Pada tata olah sampah, hasil residu makanan dan sampah organic didaur ulang menjadi biogas yang kemudian dibuah menjadi energy listrik oleh reactor, dengan begitu sampah yang dihasilkan dapat bermanfaat menjadi kompos sekaligus sumber energy terbarukan untuk menunjang sarana bangunan.

Dalam kelistrikan dan pencahayaan, pengunaan air conditioner (AC) diminimalisir dengan harapan mengurangi penggunaan energy. Desain fasad dengan atap kaca dan dinding kisi - kisi dirancang untuk membantu hal tersebut. Terdapat transparent $p v$ panel di atap untuk menyerap solar energy dan kisi - kisi digunakan argar tercipta komunikasi antar ruang dan juga sebagai ventilasi alami agar udara bisa dialirkan kedalam bangunan - ventilasi alami.

\section{Struktur Bangunan}

Struktur rangka bangunan menggunakan beton - kolom dan balok dengan lapisan penutup lantai oleh kayu. Bagian dinding kisi bangunan juga menggunakan kayu yang disusun membentuk modul pintu yang bisa dilipat sehingga ruang bisa terbuka sepenuhnya. Sedangkan untuk bahan atap dugunakan triple paned glass panel dengan lapisan luar yaitu transparent photovoltaic panel untuk menyerap solar energy dan glass panel setebal $9 \mathrm{~mm}$ untuk lapisan selanjutnya. Diantara lapisan diisi dengan gas argon ( $\mathrm{Ar}$ ) yang efektif untuk menghalau panas 
sehingga ruangan mendapatkan cahaya yang dibutuhkan - hemat energi tertapi juga tidak menjadi panas dan temperatur ruangan tetap sejuk berkat ventilasi alami kisi kayu. Bagian jembatan penghubung antar massa menggunakan metal net flooring sehingga tidak manghalau sinar matahari ke lantai bawah yang dibutuhkan tanaman.

\section{Fasad Bangunan}

Fasad tiap massa bangunan menggunakan bahan kayu yang dibuat menjadi kisi - menjadi pintu dengan modul $1 \mathrm{~m}$ sehingga kisi bisa dibuka tutup untuk privasi ruang saat kegiatan tertentu. Lapisan penutup lantai menggunakan material yang sama sehingga terlihat seragam. Pada bagian dinding luar kisi terdapat pot tanaman yang berfungsi juga sebagai railing yang dapat ditanami tanaman pangan ataupun tanaman rambat untuk menambah keasrian. Pada bagian multi - purpose space dibuat dari paving block kayu yang memiliki jarak agar tidak menghalangi penyerapan air. Sedangkan railing sky bridge terbuat dari kaca transparan dengan pegangan kayu. Fasad dipilih dengan material kayu seragam untuk menimbukan kesan natural dan asri sehingga seritme dengan landscape tapak yang hijau dan juga konsep dari proyek.

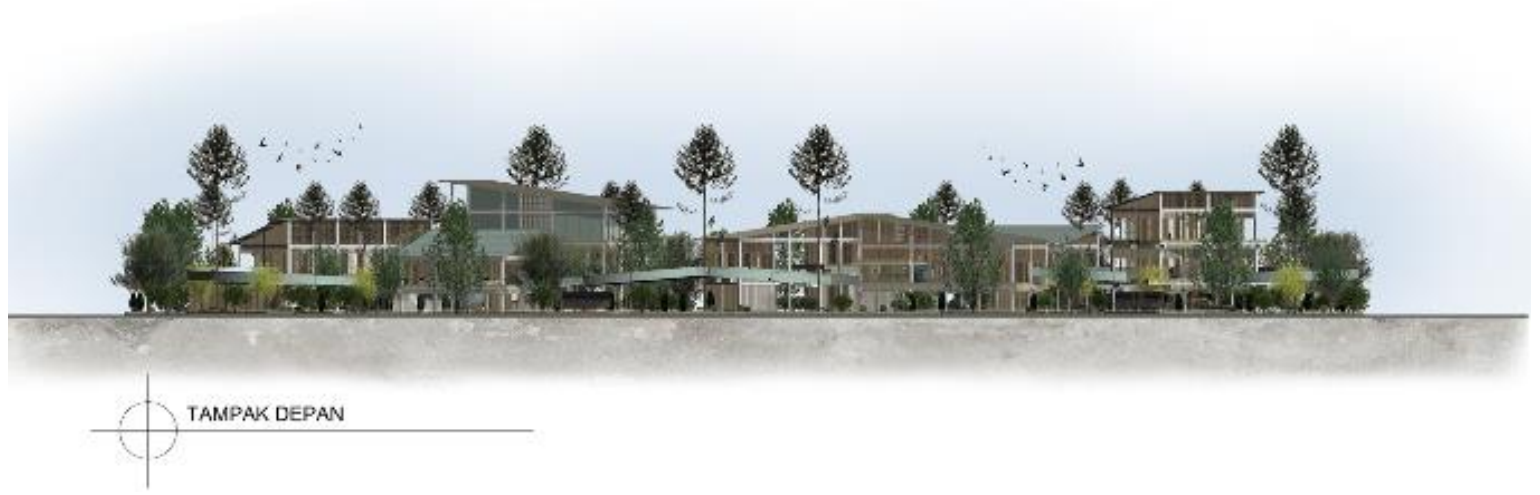

Gambar 18.Tampak depan bangunan

Sumber: Penulis, 2019

\section{KESIMPULAN DAN SARAN}

\section{Kesimpulan}

Dalam menanggapi tren yang berkembang mengenai sistem makanan global, proyek ini bertujuan untuk mengembangkan dan mempertahankan sistem makanan yang berkelanjutan secara local. Dalam upaya untuk mempersingkat rantai sistem makanan, proyek ini menyediakan wadah bagi 4 sistem pangan utama (Tanam - Distribusi - Konsumsi - Daur Ulang Makanan). Penduduk bisa belajar cara menanam dan merawat tumbuhan pangan untuk dijual maupun konsumsi pribadi. Area Distribusi berperan ganda sebagai kolektor dan distributor bahan pangan kepada yang membutuhkan. Area konsumsi ditujukan kepada pengunjung untuk makan dan bersantai. Area daur ulang makanan berperan sebagai opsi dari sumber energi terbarukan bagi bangunan. Ketika rantai makanan dipersingkat - penjual langsung bertemu pembeli, bahan pangan yang mencapai konsumen akan lebih terjamin dengan harga yang lebih rendah. Konsep dari bangunan adalah arsitektur hijau dan berkontribusi menjadi Ruang Terbuka Hijau bagi permukiman padat penduduk sehingga wadah kegiatan sosial kebanyakan diletakkan pada lantai paling bawah, sehingga mampu melayani kebutuhan kegiatan masyarakat seperti pasar segar, pusat kegiatan masyarakat dan area rekreasi. Dengan membuat area multifungsi, baik area sosial dan sistem makanan saling terhubung dan bisa digunakan bergantian. Proyek ini diharapkan mampu menjadi contoh dan memacu masyarakat untuk mewujudkan keseimbangan pangan masyarakat. 


\section{Saran}

Saran bagi upaya dalam mencapai keseimbangan pangan adalah pembuatan proyek sejenis untuk memperbaiki sistem pangan pada daerah lain terutama yang rawan menjadi target krisis pangan. Sistem sustainable dan green building dapat dikaji lebih dalam untuk pemanfaatan yang lebih menyeluruh dan maksimal bagi keberlangsungan proyek dan bangunan, misal dengan sistem air, energy serta pemilihan konstruksi dan material serta posisi tanaman pada landscape.

\section{REFERENSI}

Arifin, B., dkk. (2018). Modeling the Future of Indonesian Food Consumption: Final Report. Jakarta: World Food Programme.

BPS DKI JAKARTA. (2017). Jakarta dalam Angka. Jakarta dalam Angka 2017.

Bumi Langit. (2006). Bumi Langit Institute. Retrieved from Bumi Langit: https://www.bumilangit.org/

Calbert, R. (2018, February 5). Millennial Building Design: How millennials are changing the shape of buildings and architecture. Retrieved from LinkedIn: https://www.linkedin.com/pulse/millennial-building-design-how-millennials-changingcalbert-aia

Craven, J. (2019, June 21). A Primer on Green Architecture and Green Design . Retrieved from ThoughtCo.: https://www.thoughtco.com/what-is-green-architecture-and-greendesign-177955

Designing Buildings. (2018, September 7). Contextualism. Retrieved from Designing Buildings Wiki : https://www.designingbuildings.co.uk/wiki/Contextualism

Dewhirst, D. (2018, June 12). Millennials Are Changing Architecture from the Inside Out: Part 1. Retrieved from Linkedln: https://www.linkedin.com/pulse/millennials-changingarchitecture-from-inside-out-part-dean-dewhirst

Feist, J., \& Feist, G. J. (2013). Chapter 16 - Bandura : Social Cognitive Theory. In Theories of Personality (pp. 470-475). United States: McGraw-Hill Education.

Fram, L. (2019, Januari 3). What Is Food Distribution? (+How It Works) . Retrieved from G2: https://learn.g2.com/food-distribution

Garda-Pangan. (2018). Special Program: Sampah Makanan Melimpah. (CNN-Indonesia, Interviewer)

Garofalo, F. (2018, April 27). What is sustainable architecture: definition, concept and famous examples . Retrieved from Lifegate: https://www.lifegate.com/people/lifestyle/sustainable-architecture-definitionconcept-projects-examples

Gille, Z., Alexander, C., \& Gergson, N. (2013). Food Waste. In The Handbook of Food Research (pp. 471-485). Bloomsbury.

Goldman Sachs \& Co. LLC. (2015, March). DATA STORY : MILLENNIALS. Retrieved from Goldman Sachs: https://www.goldmansachs.com/insights/archive/millennials/index.html

Kearney, J. (2010). Food consumption trends and drivers. Philosophical transactions of the Royal Society of London. Series B, Biological sciences, 2793-2807. doi:10.1098/rstb.2010.0149

Kresna, M. (2017, Februari 22). DKI Hasilkan 4 Ribuan Ton Sampah Makanan Per Hari. Retrieved from Tirto.id: https://tirto.id/dki-hasilkan-4-ribuan-ton-sampah-makananper-hari-cjti

Lopez, N. (2017, April 1). TMD STUDIO. Retrieved from A Medium Corporation: https://medium.com/studiotmd/gen-y-millennials-in-architecture-476e9839321b 
Margarete. (2018, June 1). 1\# ARCHITECTURAL PSYCHOLOGY: The Influence of Architecture on our Psyche. Retrieved from A Medium Corporation: https://medium.com/archilyse/1the-influence-of-architecture-on-our-psyche-f183a6732708

Papargyropoulou, E.,dkk. (2014). The food waste hierarchy as a framework for the management of food. Journal of Cleaner Production, 1-10.

Rossum, T. v. (2019, April 4). Vertical Farming. Retrieved from Agrodite: https://agrodite.com/vertical-farming/

Rouse, M., \& Haughn, M. (2014). Essential Guide. Retrieved from TechTarget.com: https://whatis.techtarget.com/definition/millennials-millennial-generation

SH Architecture. (2016, March 3). What is Sustainable Architecture? Retrieved from SH Architecture: https://sh-architecture.com/2016/sustainability/what-is-sustainablearchitecture

The Economist Intelligence Unit. (2018). Fixing Asia's Food System. Retrieved from https://eiuperspectives.economist.com

Vats, S. (2017, September 12). Impact of Architecture on Human Psychology. Retrieved from A Medium Corporation: https://medium.com/@srkshivangi.01/impact-of-architectureon-human-psychology-f0b637714603

Waste4Change. (2014). Retrieved from https://waste4change.com/beta/official/.

Wikipedia. (2015). Wikipedia, The Free Encyclopedia. Retrieved from Article: https://id.wikipedia.org/wiki/Pertanian_vertikal 